\title{
Legal Aspects which Implement Good Practice Measures in the Manage- ment of Construction and Demolition Waste
}

\author{
Mercedes del Río Merino ${ }^{1 *}$, Justo García Navarro ${ }^{2}$ and Paola Villoria Sáez ${ }^{1}$
}

\author{
${ }^{1}$ Building Technology and Environment (TEMA) Research Group, Polytechnic University of Madrid, School of Building \\ Engineering, Spain \\ ${ }^{2}$ Sustainability in Construction and Industry Research Group (giSCI), Polytechnic University of Madrid, Ciudad \\ Universitaria $s / n, 28040$ Madrid, Spain
}

\begin{abstract}
The construction industry, one of the most important ones in the development of a country, generates unavoidable impacts on the environment. The social demand towards greater respect for the environment is a high and general outcry. Therefore, the construction industry needs to reduce the impact it produces. Proper waste management is not enough; we must take a further step in environmental management, where new measures need to be introduced for the prevention at source, such as good practices to promote recycling.

Following the amendment of the legal frame applicable to Construction and Demolition Waste (C\&D waste), important developments have been incorporated in European and International laws, aiming to promote the culture of reusing and recycling. This change of mindset, that is progressively taking place in society, is allowing for the consideration of $C \& D$ waste no longer as an unusable waste, but as a reusable material.

The main objective of the work presented in this paper is to enhance C\&D waste management systems through the development of preventive measures during the construction process. These measures concern all the agents intervening in the construction process as only the personal implication of all of them can ensure an efficient management of the $C \& D$ waste generated.

Finally, a model based on preventive measures achieves organizational cohesion between the different stages of the construction process, as well as promoting the conservation of raw materials through the use and waste minimization. All of these in order to achieve a C\&D waste management system, whose primary goal is zero waste generation.
\end{abstract}

Keywords: Construction and demolition waste, Waste management, Good practices.

\section{INTRODUCTION}

In general, Construction and Demolition Management Plans are based on a hierarchical principle, establishing as a priority the prevention of $C \& D$ waste generation. This is followed by the need to reuse and recycle the waste when possible (by means of selective recuperation at origin so that these materials can further be treated -both recyclable materials and the ones to be sent to the treatment plant). Thirdly, the waste needs to be energetically valorized, extracting everything suitable of being reused or recycled. The final disposal at the dump should be the last option to be considered, for it is the least satisfactory one [1].

In spite of this, and basically due to the fact that in the C\&D waste recycling the economic and environmental issues meet, not enough improvements have been reached in waste management in order to correct the serious effects this issue produces on the environment.

A great number of European countries have introduced legal measures, in later years, to improve the $C \& D$ waste management [2].

*Address correspondence to this author at the Polytechnic University of Madrid. School of Building Engineering, Spain; Tel: 9133676 46;

Fax: 9133676 44; E-mail: mercedes.delrio@upm.es
Among the measures taken up, several of them can be highlighted due to their efficiency:

- The inclusion of a C\&D waste management plan within the architectural design project.

- Making the payment of deposits or financial guarantees compulsory as a condition to receive the construction work permit.

- Promoting the use of products and waste originated from the valorisation of $C \& D$ waste.

In addition, construction companies have been incorporating additional measures [3]. These measures concern all the agents intervening in the construction process as only the personal implication of all of them can ensure an efficient management of the C\&D waste generated. The application of these measures can be directed to both total and partial demolition works, where logically, the volume of C\&D waste generated is much greater [4].

A number of measures to improve the waste management is further detailed in this article. These aspects should be included in a Good Practices Manual and be incorporated in the Report on Waste Management of the companies intervening in the construction process. 
The different measures, which regulate the production and management of C\&D waste, are the following:

\section{LEGAL MEASURES}

As it has already been stated in the introduction, in later years, a great number of European countries have introduced legal measures to improve the C\&D waste management. In November 2008, the European Parliament passed the 2008/98 Directive on waste which aims at introducing a new approach, and does not only consider the waste stage but also all the life cycle of the products and materials, in such a way as to reduce the environmental impact of waste management [5]. This Directive demands the adoption by each Member State, of the necessary measures to ensure that by 2020 , there is a $70 \%$ in weight increase in the treatment, recycling and other valorization operations of non-hazardous C\&D waste, excluding the ones in the 170504 category of the European Waste Catalogue (EWC) [6].

In Spain, the Royal Decree 105/2008 [2] and the II National Plan of Construction and Demolition Waste (II PNRCD in Spanish acronym) for the 2008-2015 period, are in force [7]. This plan establishes new objectives for 2015 based on the experience of the I PNRCD, which are still far from being reached presently. The causes for this inability to fulfill the Plan are the intensive construction activity from the last years, the low cost of dumping and the easy availability of natural resources.

Among the different measures that have been adopted to solve this situation, the implementation of a C\&D waste management project can be pointed out due to its efficiency [8].

A requirement for both local governments and State government departments to develop waste management strategic plans provides opportunities to encourage better management of C\&D wastes from residential, commercial and industrial developments and at all project stages [9].

Within the management plan of C\&D waste, it is compulsory to design a technical project that should be presented together with the urban licence of demolition or excavation. This project includes an assessment of the approximate volume and characteristics of the waste which is going to be generated, as well as the projected operations for separation and selective recollection together with the specification of the plant or recycling installations where the waste is to be managed [10].

All the data described above should form a technical report in the design project called Report on Waste Management. This report should include the following information:

- Final destination of the waste. If the debris is to be absorbed (recycled or reused) at the same construction work, the different special constructive dispositions adopted should be justified in the technical specifications so that they can be performed.

- A survey of the surface availability to perform the selective separation operations. If these operations are necessary, space to carry them out should be planned and should be indicated in the design drawings.
- Location of the closer authorized dumps (controlled deposits) and recycling plants. As in the case of the controlled deposits, the transportation distance and the recycling costs -regarding the degree of separation the waste implies-- should be considered.

- Type of construction to be demolished. These include the kind of construction systems used, the materials used, and the constructive elements liable to be reused.

- Volume of the most abundant materials to be recycled or that have to be disposed in a dump (controlled deposit). The total volume of materials to be discarded and of materials to be recycled should be assessed and justified [11].

- Cost of the deposit. Once the justified assessment of the total amount of waste to be originated has been carried out, the cost of the deposit can be stated. The approximate dates when the waste is going to be generated should also be included in the waste managing report, detailing this operation in the construction program, with the necessary space and the needed economic and material resources.

Before starting the construction process, the C\&D waste management plan should be carried out. This plan is specific for the construction work and it is based on the Report on waste management included in the design project. The C\&D waste management plan, should necessarily include the following information and refer to the following aspects:

- An estimated approach of the amount, in tons and cubic meters of the $C \& D$ waste to be generated in the construction work.

- The operations of reuse, valorization or final disposal of the waste. Waste should be reused on site or saved for subsequent reuse to the greatest extent possible. Dumping should only be considered as the final solution.

- The drawings of the installations provided for the storage, handling or any other managing operation of the C\&D waste to be carried out on the working site. These premises can later be changed and adapted to the particular characteristics of the construction and the constructive elements -always in agreement with the managing board of the construction.

- The descriptions to include in the technical specifications of the design project, regarding storage, handling or any other managing operation of the C\&D waste to be carried out on the working site.

- An assessment of the predicted cost for the correct management of C\&D waste, which should be stated in the project budget in a separate section.

- In addition, a document certifying that the C\&D waste produced in the construction work has been handed over to a valorization plant or to a treatment plant by the authorized waste management agency, has to be provided. It is compulsory to maintain the corresponding documents for each natural year and for the following five years. 
- On the other hand, the C\&D waste should be classified in fractions when a certain volume of generated C\&D waste is surpassed. If the owner cannot ensure the performance of this operation due to the lack of physical space, he should rely on an authorized agent who will certify the correct execution of the processing.

- In the exceptional event of the previous fulfilment implying an increase in the costs not justified by the environmental benefits, the competent body in environmental matters of the region/province can free the owner of the C\&D waste of the obligation to classify part of the previous fractions.

Providing indicators regarding the production $\mathrm{C} \& \mathrm{D}$ waste for in each construction project, has become an essential need. $[12,13]$. These indicators should necessarily be at the service of architects and engineers, so that the volume of C\&D waste suitable to be generated can be established with certainty in the design phase. At the same time, the most appropriate destination for each of the C\&D waste category and its economic cost should also be planned.

\section{LOCAL AUTHORITIES MEASURES}

Local bodies, regarding urban planning licences, can condition the permission for the construction works providing a deposit or an equivalent type of financial guarantee to correctly manage the $C \& D$ waste produced in the construction. The municipal services determine the quantity of the deposit, which should be proportional to the amount of waste generated.

In order to receive the deposit refund, the company has to certify --in a document form-- the correct management of the waste generated.

In this way not only the main objective of prevention and reduction of C\&D waste could be reached, but also the promotion of reusing and recycling of the valorised products, as well as fulfilling and ensuring the correct treatment of the waste that needs to be eliminated [14]. Thus, maximizing the recuperation of the resources contained in C\&D waste, the construction activity will contribute to a more sustainable development.

According to this, the Administration is moving towards greater control and inevitably, to a reduction in the number of authorised landfills, as well as discouraging discharging by establishing a clear fiscal framework. In fact, in recent years a notable increase of the discharge rates of incontrolled deposits of C\&D waste has been stated. Disposal in landfill costs will continue to increase in the future. For example, since the publication of the first version of the Regional Plan for C\&D waste of Madrid, the amount which must be paid for $C \& D$ waste dumping in some deposits have increased from $€ 1.20 \mathrm{~m} 3$ to $9 € / \mathrm{m} 3$ [15].

Among measures to improve C\&D waste management to be developed by local authorities are the following:

- Development of regulations establishing the requirements for quality of recycled materials from C\&D waste, providing technical guarantee of them within the market.
- Adjusting the economic instruments to promote the prevention and recycling of C\&D waste.

- Promoting the construction of C\&D waste treatment plants. Institutional support (when it is not of public promotion) for its implementation, licensing, management and financing.

- Planning realistically the $C \& D$ waste production through effective policy measures and valid planning instruments.

- Effectively controlling the production and management of C\&D waste.

- Consolidating a common and uniform framework of environmental indicators, C\&D waste production, reuse and recycling at the level of the regional administration, in order to follow the "ecological goals" of the PNRCD.

- Clearly identifying the producer of C\&D waste (developer - builder) responsible for the management of the C\&D waste.

- Supporting r\&d programmes for the improvement of the management of C\&D waste, both on the construction site, as in the treatment of C\&D waste (recycling plants...) and on the efficient use of products coming from recycling.

\section{MEASURES OF THE CONSTRUCTION TEAM}

In general, large construction companies (FCC Construcción, Acciona...) are aware of the importance of the preservation of the environment and the responsible use of available resources towards society. Therefore, they promote environmental excellence, setting annual objectives for continuous improvement, while minimizing the negative impacts of processes, products and enhancing positive impacts.

However, the majority of the building works in Spain are constructed by small size construction companies, which, generally, do not determine annual environmental objectives or require an environment department in their organization, as is the case in large enterprises. In this sense, small businesses must be involved in the minimization of negative impacts arising from the construction process, setting annual targets to improve the environment.

As an example, the objectives proposed by the major companies include the following:

- $\quad$ Providing specific environmental training for workers. (At least $100 \mathrm{~h}$ specific training).

- Campaign of good environmental practices among workers.

- Implementation in the construction works of Good Practices which has resulted in a total reduction of 70,993 tonnes of dust.

- Increasing the volume of waste separated according to recycling.

- Increasing by $10 \%$ the volume of paper for recycling.

- Decreasing by $10 \%$ the volume of hazardous waste generated. 
Another measure carried out by construction companies is the participation and promotion of research projects whose purpose is to improve $\mathrm{C} \& \mathrm{D}$ waste management. Research projects developed in this field, include the following:

- $\quad$ LOGRO Project [16], framed in a PROFIT developed by FCC Construcción, AUSA and ITEC, Institute of technology companies of Catalonia.

- Project RECONS [17], developed by the Guild of builders of Barcelona, which aims to make viable a system of environmental management in small and medium-sized construction companies.

Both projects are based on the waste management hierarchy, with waste prevention and minimization being the first priority followed by reuse and recycling. During construction works, there are numerous opportunities to reduce and recycle the waste generated [15] are present.

Therefore, the primary effort should be to engage in waste prevention and reduce the amount of waste generated in the first place. Prevention is financially favourable as it reduces the purchase of construction materials and avoids the need to remove wastes from site [18].

Due to the large quantity and high potential for recovery of the C\&D waste [14], we propose a management model based on best practices associated with different types of C\&D waste generated through the implementation on site of a Good Practice Manual.

This model is based on a selective separation at source. The management model can be defined from its operational elements:

- Planning the generation in the main categories of waste throughout the construction period. Knowing when and the approximate amount generated in different categories of waste is essential for costeffective management of space and the work resources. This "planning" requires no management show off; the relatively recurring typology of a significant number of projects (especially in the residential sector), the experience of those responsible for the construction works and the collaboration of management companies, undoubtly provide and avoid many problems.

- Separation at source and collection: A key to the proper management of the C\&D waste. The waste must be managed according to its nature and following the principle of hierarchy. The classification of C\&D waste in construction works should approach, as much as possible, --temporary and spatially-- the waste generation process. So, for example, it will always be cheaper and more effective that workers working directly on site, separate the wood waste of concrete, plastic and sand produced by the removal of a reinforcement, than carrying out this separation once the waste has been deposited in the container.

- The transportation of waste must be performed by authorized processors and recyclers.

- The treatment of the C\&D waste will be held either by producers or by external treatment centres.
In general, a conventional residential building work could save about 70-75 per cent in final management costs with a substantial change in the management practices of waste on site. These savings, which might seem exorbitant at first, are induced by the implementation of measures on site aimed at improving the $C \& D$ waste management.

These measures concern all the agents intervening in the construction process, as only the personal implication of all of them can ensure an efficient management of the C\&D waste generated. A fluid collaboration, a clear allocation of responsibilities and, above all, the alignment of economic interests, will prove vital for the necessary change occurring in the construction works. The application of these measures can be directed to both total and partial demolition works, where logically, the volume of C\&D waste generated is much greater.

A number of measures to improve the waste management are further detailed, and can be applied to all types of construction projects, irrespective of location or complexity, including new buildings, refurbishments and infrastructure works.

\subsection{Designer}

Design criteria and design philosophy have been identified as potentially major contributors to the quantity and type of $C \& D$ waste generated on any project.

It is essential to plan with solvent indicators during the design phase, the amount of C\&D waste according to the EWC category and their moment of generation in the construction works. This planning will take into account the forecast of the C\&D waste generation, and will be the basis for drawing up the corresponding specifications with conditions and budgets.

Therefore, the designer when designing a building, has to consider several factors such as:

- $\quad$ The envelope constructive elements by the juxtaposition of layers of the adequate materials.

- $\quad$ The use of standard material sizes as much as practical, to avoid cut-off waste in masonry, gypsum board, block, panels etc.

- $\quad$ To construct using dry assembly (screws, nails, clips) the disposition of materials in successive layers facilitating the selective homogeneous waste.

- $\quad$ The material supplier will recollect the packaging and apply a responsible management process.

- To plan construction works in such a way that no waste is originated or that the construction site assimilates all the waste originated.

- $\quad$ To design the project in such a way that the excavated soil/topsoil can be carefully set aside and used as landscaping material in the completed development.

- $\quad$ To introduce in the project the reused elements coming from previous constructions.

- $\quad$ To introduce in the work plan (in the design stage) the proposals of the constructor to minimize, reuse and classify the waste on site. 


\subsection{Construction Manager}

The construction works manager should take into consideration, the following issues:

- When planning the construction and demolition process:

- To analyze in advance the waste generated in the construction and demolition using available resources to help the estimation of the types/amount of waste. For example, using waste disposal records from previous projects.

- $\quad$ To identify and quantify, in each of the construction phases, the amount and characteristics of the waste to be originated in the execution process.

- To plan individual good practice methods for each type of C\&D waste generated in a construction phase, especially in the construction phase where greater generation is expected. For example, bricklaying is one of these phases, which generates more ceramic waste; therefore, construction managers should plan specific measures to prevent this type of waste. As an example of these ceramic waste measures we can include:

- Not over-ordering materials.

- Storing in packaging to protect them.

- Storing away from vehicle movements.

- Preventing ready-mixed mortar from drying out.

- Avoid cutting and chasing.

- Reuse excess bricks or blocks, either on or off site.

- If damaged, use the material as hardcore on site access roads.

- Segregating and recycling packaging waste.

- Reduce the dust nuisance from cutting and chasing.

To plan the way in which the management of waste originated in the works will be dealt with, considering distances, costs, procedures, convenience and other pertinent factors. It is necessary to determine the valorization of the waste, whether it will be reused, recycled or rather serve to recuperate the energy stored. The aim is to have available the means and processes needed, so that the resulting waste is in best conditions for its valorization.

- $\quad$ According to this, it is important to perform a waste management plan to optimize the valorization of the waste and surplus materials. It is necessary that all main contractors get involved in the development of the Waste Management Plan.

- To encourage the classification of the waste produced, so that valorization and processing of the controlled disposal is easier.

- To elaborate criteria and specific recommendations for improving waste management. The purpose is to analyze the technical conditions needed, and before starting the construction work to define - preferably in written form-a collection of good practices for the correct management of the construction work.

- $\quad$ To find a processor or recycler that will accept the mixed $C \& D$ waste for recycling and will provide documentation of the amount recycled.

- $\quad$ To arrange a directory of the nearest waste purchasers and recyclers.

- $\quad$ To designate a C\&D Waste Manager or a Recycling Coordinator, who will be responsible for developing the details of the Plan and monitoring its progress. This C\&D Waste Manager may well be different persons over the life-cycle of the project, but in general, it should be a reliable person chosen from within the Planning/ Design/Contracting Team. This person, should be technically competent and appropriately trained, and will be responsible of ensuring that the objectives and measures within the Project Waste Management Plan are performed.

- $\quad$ To plan training courses regarding $C \& D$ waste for the personnel participating in the construction process; receiving the necessary information to manage the different $\mathrm{C} \& \mathrm{D}$ waste properly.

- When signing the contracts with the subcontractors:

- $\quad$ To be responsible for the purchase of raw materials and for the management of wastes arising from their activities [19].

- $\quad$ To limit the maximum volume of waste that can be generated for each activity.

- To establish the economic sanctions to be applied when the predicted volume is exceeded; to arrange regular meetings with the subcontractors to coordinate the waste management.

- When buying the materials:

- $\quad$ To minimize and reduce the amount of raw materials used and that of the waste being originated.

- To submit recycled products when they meet the specifications.

- $\quad$ To use recycled materials for job site uses, such as temporary construction, office supplies, and collection containers.

- To consider the wide range of commonly available recycled products, including steel products, insulation, concrete products, fiberboard, plastic, roofing, and flooring.

- To foresee the amount of materials needed for the construction work. Emphasizing the potential for certain purchasing procedures to contribute to the reduction of an excessive on site material waste is essential. An excess of materials, is not only expensive but also originates a greater volume of surplus remains.

- To select suppliers which take back packaging, pallets, unused or scrap materials.

- $\quad$ To order materials accurately and as needed, to minimize the risk of damage. 
- $\quad$ To plan the storage of materials supply out of the areas of transit in the construction site, keeping them well packed and protected until the moment of their use. A common practice is to order an extra $5-10 \%$ of materials to allow for site waste by damage, spillage, under-supply and vandalism. These figures should be reduced.

- When storing C\&D waste:

- $\quad$ The minimum equipment is formed by two containers and a deposit for liquids and potentially hazardous materials. One of the containers is for stone debris (coming mainly from the construction) and the other container serves for commonplace waste (paper, metals, plastic, etc.).

- If there are nearby recycling industries specialised in other type of waste, not having been detailed before, an additional container can be installed.

- When plaster renders are performed, a specific container for keeping large quantities of gypsum paste waste needs to be placed, since it becomes a great pollutant when together with stone materials.

- $\quad$ The containers, bags, deposits and all other recipients for storage and transportation of the different types of waste have to be clearly labelled.

- In construction works with enough waste volume, equipment for grinding the debris is needed to produce recycled aggregate.

- Conclusions of the efficient waste management experience should be drawn, in order to be applied to other similar construction works (waste disposal records).

\subsection{Site Manager}

The site manager has:

- $\quad$ To ensure that all agents intervening in the construction know who is responsible for: reporting to the site manager; reporting to the appropriate environmental regulators; as well as understanding their obligations in relation with waste.

- $\quad$ To ensure that all agents carry out the norms and orders dictated by the technical manager.

- $\quad$ To encourage the interest to reduce the resources used and the waste volume originated. The separation of plastics, wood, etc., that considerably increase the volume of C\&D waste (and, therefore, the number of containers), can be given to recyclers and evaluators, who in most cases, will withdraw them for no cost or at a cost much lower than that of the rest of the waste. Some waste, such as steel, even more so today, has a market price, which can generate economic incomes for the construction work.

- $\quad$ To promote the applications of the waste on site. The debris originated at the construction site is not considered as waste if it is reused at the working site.

- $\quad$ To plan a protected area for the storage of materials guarded from any actions that could make them unusable.
- $\quad$ To arrange the space available for the storage of waste and select the most appropriate containers for each type of waste.

- $\quad$ To concentrate on a few key materials to be sourced separately, although their generation does not exceed the amount stated in the law.

- $\quad$ To check the movement of the waste so as not to leave any uncontrolled remains.

- $\quad$ To control that liquid waste is not mixed together with other organic waste and as a result becomes contaminated.

- To prevent the production of dust from an uncontrolled handling of powdery materials.

- To register a list of each container leaving the construction site in order to develop waste disposal track records.

- $\quad$ To monitor the recycling progress periodically, and compare the recycling rate to the requirements established in the C\&D waste management report.

- To implement, in each of the construction phases, individual good practice measures related with the different types of $C \& D$ waste generated in each phase.

\subsection{Working Personnel}

The site personnel have:

- $\quad$ To fulfil the norms and orders dictated by the construction manager regarding waste control.

- $\quad$ To actively participate in the improvement of waste management.

- $\quad$ To separate the waste when it is originated. A segregation of C\&D waste at origin allows to optimize the reuse "in situ" of ceramic materials, concrete waste.

- $\quad$ To place the waste in containers, bags or adequate deposits.

- To avoid bad practices, which in an indirect way, originate unpredicted waste and a misuse of construction materials.

- When a supply of materials is ordered in excess, energy and materials are wasted and more waste is originated.

\subsection{Subcontracted Companies}

The companies, in general, have to:

- Assume the materials packaging and the surplus of materials and products of the construction. As a general norm, the waste producer is the one responsible for them.

- To know and fulfil all the obligations referred to waste, and the norms and orders dictated by the technical manager.

- $\quad$ To predict the maximum volume of waste the activity can generate, so as to minimize it and classify it in the correct way. 
- $\quad$ To make proposals of possible solutions, to the project designer and to the construction manager, to improve reduce, reuse or recycle the construction elements and the surplus.

\section{CONCLUSIONS}

Construction and demolition waste is a major component of the solid waste stream. Each year 40.000.000 tones of C\&D waste are generated in Spain. This waste should be recognized as a valuable resource since large quantities of it could either be recycled or reused.

Until recently, C\&D waste has been overlooked in the efforts to reduce waste dumped in landfills, with the emphasis being placed on domestic recycling. This study has been undertaken to identify key issues that will help in the development of management strategies to improve C\&D waste minimization. Nevertheless, the speed and degree to which this inclusion should be carried out is determined by the economic viability of the process.

Public administrations are dedicating great efforts to improve the legislation of $C \& D$ waste and this article includes the last measures being achieved in this area. In addition, as it has been shown, only with the implication of all the agents and local administrations and with a strong enforcement and severe tracking of the proposed measures, an efficient management of the waste can be reached.

Many aspects of the construction waste management should be considered, both in the design stage and in the proper construction stage as well as in the demolition or reconstruction phase. All the agents intervening in the construction process should be involved and concerned with these issues. It is a fact that a good management is the one considering all the aspects of the construction activity and, in such a way, management of C\&D waste can be improved and could be more adequately used.

Finally, these aspects should be included in a Good Practice Manual where the waste management follows the principles of the waste hierarchy. Good practices involve going beyond the current baseline performance of the construction industry, which has historically focused on meeting its legal obligations only.

\section{ACKNOWLEDGEMENTS}

None declared.

\section{CONFLICT OF INTEREST}

None declared.

\section{REFERENCES}

[1] Conferencia Nacional sobre Prevención de Residuos. Madrid, Ministerio de Medio Ambiente. 2006
[2] Gobierno de España. Real Decreto 105/2008, de 1 de Febrero, por el que se Regula la Producción y Gestión de los Residuos de Construcción y Demolición. Ministerio de la Presidencia. España, 2008.

[3] M. Marrero, and A. Ramirez de Arellano, "Building cost system andalusia: Application to construction and demolition waste management", Constr Manag Econ., vol. 28, pp. 495- 507, 2010.

[4] M. Del Río, P. Izquierdo, and I. Salto Weis, "Ethical and legal aspects of the use and recycling of masonry waste in Spain", In: Proceedings of Masonry Conference, British Masonry Society. London, 2006.

[5] Directive 2008/98/EC of the European Parliament and of the Council of 19 November 2008 on waste. Official Journal of the European Union 22/11/2008.

[6] European Waste Catalogue (EWC). Gobierno de España. Orden MAM/304/2002, de 8 de Febrero, por la que se Publican las Operaciones de Valorización y Eliminación de Residuos y la Lista Europea de Residuos. Ministerio de Medio Ambiente. España, 2002.

[7] II Plan Nacional de Residuos de Construcción y Demolición (II PNRCD) 2008-2015. Capítulo 12 del Plan Nacional Integrado de Residuos (PNIR), Ministerio de Medio Ambiente y Medio Rural y Marino. BOE 49 de 26/02/2009, pp. 19938-19948.

[8] V.W.Y. Tam, "On the effectiveness in implementing (a waste management-plan method in previous construction", Waste Manag., vol. 28, pp.1072-80, 2008.

[9] P. Villoria, and M. Del Río, "Gestión de residuos de construcción y demolición (RCD) en obras de edificación. Buenas prácticas en Albañileria." In: Proceedings of I Congreso Nacional Investigación Aplicada a la Gestión de Edificación (COIGE). Alicante, 2010.

[10] J. Solís-Guzmán, M. Marrero, M.V. Montes-Delgado, and A. Ramírez de Arellano, "A Spanish model for quantification and management of construction waste". Waste Manag., vol. 29, pp. 2542- 8, 2009.

[11] Guía de aplicación del Decreto 201/1994, regulador de los escombros y otros residuos de la construcción. Agencia de Residuos de Catalunya. Instituto de tecnología de la Construcción de Cataluña (ITEC), 2005.

[12] G. Rodríguez, F.J. Alegre, and G. Martínez, "The contribution of environmental management systems to the management of construction and demolition waste: The case of the Autonomous Community of Madrid (Spain)", Resour Conserv Recycling, vol. 50, pp. 334-49, 2007.

[13] C.S Poon, A.T.W Yu, and L. Jaillon, "Reducing building waste at construction sites in Hong Kong", Constr Manag Econ., vol. 22, pp. 461-70, 2004.

[14] P. Charles, and S. Connolly, Environmental good practice on site. Construction Industry Research and Information Association (CIRIA). CIRIA report C650. $2^{\text {nd }}$ ed. London, 2005.

[15] Comunidad de Madrid. Plan Regional de Residuos de Construcción y Demolición 2006-2016. Comunidad de Madrid, 2006.

[16] M.T. de Ugarte i Peyró, "Optimización de la gestión de los residuos de la industria de la construcción. Proyecto LOGRO", In: Proceedings of Congreso Nacional de Medio Ambiente (CONAMA)VII. Madrid, 2004.

[17] Gremio de Constructores de Barcelona. Proyecto RECONS. Proyecto LIFE Comisión Europea, 2004-2006.

[18] P. Baleirón Pampin, and M.O. García Navarro, "Residuos de Construcción, Situación Actual y Retos de Futuro. Actuaciones Sostenibles Mediante su Reciclaje en Obra”, In: Proceedings of Congreso Nacional de Medio Ambiente IX (CONAMA 9). Acciona Infraestructuras, 2008.

[19] V.W.Y. Tam, L.Y Shen, and C.M. Tam, "Assessing the levels of material wastage affected by sub-contracting relationships and projects types with their correlations", Build Environ., vol. 42, pp. 1471-7, 2007. 